\title{
The optimal regimen of oral tranexamic acid administration for primary total knee/ hip replacement: a meta-analysis and narrative review of a randomized controlled trial
}

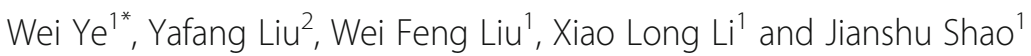

\begin{abstract}
Background: Oral tranexamic acid (TXA) has been demonstrated to reduce the blood loss in primary total knee and hip arthroplasty, but the optimal regimen of oral TXA administration is still unknown. This study aimed to find the best number of administrations of oral TXA for primary total knee and hip arthroplasty.

Methods: The PubMed, Embase, and Cochrane Library databases were searched for relevant studies published before March 20, 2020. Studies clearly reporting a comparison of multiple administrations of oral TXA for total hip/ knee replacement were included, and the total blood loss (TBL), intraoperative blood loss (IBL), decline in hemoglobin (DHB), deep vein thrombosis (DVT), intramuscular venous thrombosis (IVT), length of hospital stay (LOS), and transfusion rate were evaluated. The weighted mean differences and relative risks were calculated using a fixed effects or random effects model.

Results: Nine studies involving 1678 patients were included in this meta-analysis (TXA 1363 (one administration, 201; two administrations, 496; three administrations, 215; four administrations, 336; five administrations, 115); placebo 315); the results show that compared with placebo groups, oral TXA could significantly reduce the TBL, IBL, DHB, LOS, and transfusion rate. In addition, the incidences of IVT and DVT were similar between the TXA and placebo groups. Moreover, two administrations of oral TXA significantly reduced the TBL and DHB compared with one administration, three administrations of oral TXA were better than two administrations, and four administrations of oral TXA were better than three administrations.

Conclusion: Our results suggested that oral TXA could significantly reduce the blood loss and the length of hospital stay but could not increase the incidence of DVT and IVT for total joint replacement patients; additionally, the effectiveness of oral TXA administration increased as the number of administrations increased.
\end{abstract}

Keywords: Oral, Multiple dose, Tranexamic acid, Total knee/hip arthroplasty

\footnotetext{
*Correspondence: ye_wei8912@163.com

'Department of Orthopedics Medicine, Wujin Hospital Affiliated with Jiangsu University, Changzhou 213000, China

Full list of author information is available at the end of the article
}

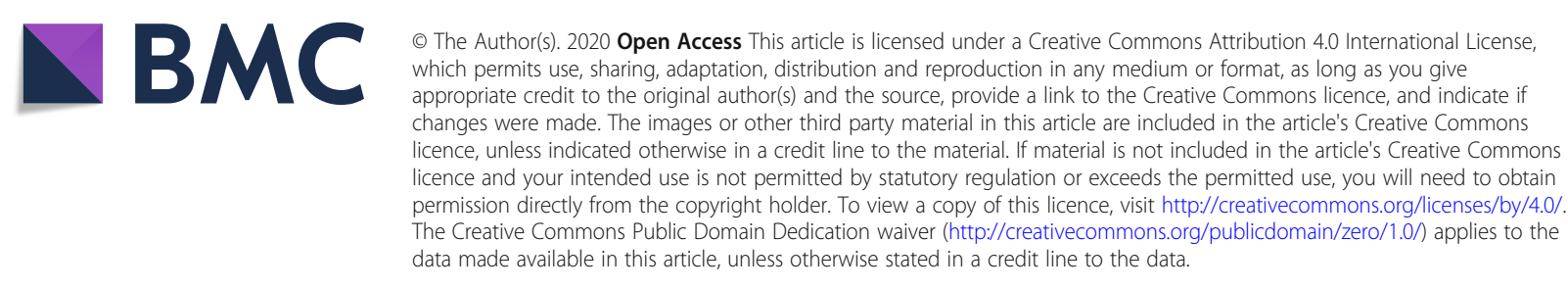




\section{Introduction}

Total joint arthroplasty (TKA/THA) is a reliable surgical method for patients who suffer from moderate-to-severe degenerative knee or hip joint diseases and osteoarthritis pain, but controlling perioperative bleeding is a major problem for orthopedic surgeons. Many previous studies have reported that the estimated total blood loss was between $800 \mathrm{ml}$ and $1800 \mathrm{ml}$ in total joint replacement patients $[1,2]$. To overcome this problem, several methods have been used to reduce perioperative blood loss, such as tourniquet use, blood transfusions, administration of iron supplements, and the application of anti-fibrinolytic drugs [3-6]. Transformations have various limitations, such as prolonging the patient's rehabilitation time and extending the length of hospital stay. In addition, transfusions incur a considerable cost and are associated with the risk of side effects, infectious diseases, inhibition of the immune system, and so on [7-9]. Tranexamic acid (TXA) is a synthetic agent that exerts its antifibrinolytic effects by inhibiting plasminogen. TXA inhibits plasminogen activation by binding plasmin to fibrin, which leads to clot stabilization and reduces blood loss. In addition, many previous publications have confirmed that TXA is a simple, inexpensive, and effective drug for reducing perioperative blood loss in total knee arthroplasty regardless of intravenous, intra-articular injection, or oral administration [10-14]. However, there is still no consensus about which route is the best for administering TXA to total joint arthroplasty patients, and in recent years, some studies have recommended multiple administrations of oral TXA. However, there is still no consensus regarding the optimal regimen of oral tranexamic acid administration; therefore, we conducted a study to determine the most effective regimen of oral TXA for primary total knee and hip arthroplasty patients.

\section{Materials and methods}

\section{Search strategy}

Pubmed, Cochrane library, and Embase databases were searched independently by two investigators to retrieve relevant studies published before March 20, 2020. The search criteria "total knee/hip arthroplasty," “TKA/THA," "total joint replacement," "TKR/THR," "tranexamic acid," "TXA", "oral," and "multiple dose" were used in key words for search. All studies selected were reviewed independently by the authors and examined for broadening the potential studies through the "related articles" function. Thus, the reference lists of the included articles were also manually checked to find relevant studies that were not found during the database searches.

\section{Inclusion criteria}

(1) The adult patients with knee or hip joint degenerative disease and received primary TKA/THA, (2) TXA oral administration include different dose groups, (3) examination includes anyone among total blood loss (TBL), intraoperative blood loss (IBL), the decline in hemoglobin (DHB), deep vein thrombosis (DVT), intramuscular venous thrombosis (IVT), the length of hospital stay (LOS), and the transfusion rate.

\section{Exclusion criteria}

(1) Total joint replacement is not for joint degenerative diseases such as trauma, tumors, or bilateral joint replacement; (2) study only report one oral group or case report; and (3) animal or laboratory study.

\section{Data extraction}

Each article's variables and outcomes of interest and assessment of the methodological quality were reviewed independently by two readers. If there was a difference of opinion, the problems were resolved through discussion and consensus. The methodological quality of the trials was assessed through the Cochrane Handbook for Systematic Reviews of Interventions 5.1 .

\section{Statistical analysis}

The statistical analysis was performed using Review Manager 5.1 for Windows System (Cochrane Collaboration, Nordic Cochrane Centre, Copenhagen, Denmark). Categorical dichotomous variables were analyzed with relative risks (RRs), continuous variables were assessed with the weighted mean difference, and $P<0.05$ was considered statically significant; the $95 \%$ confidence intervals (CIs) were reported. Heterogeneity was considered significant if the $P$ value was less than 0.1 . The value of $I^{2}$ statistics was used to assess the degree of heterogeneity $\left(I^{2}\right.$ $<25 \%$, no heterogeneity; $I^{2}=25-50 \%$, moderate heterogeneity; $I^{2}>50 \%$, large or extreme heterogeneity); if $I^{2}>50 \%$, a fixed-effects model was used. The presence of publication bias was assessed by a visual inspection of a funnel plot and the Begg and Egger tests (with $P<0.05$ considered statistically significant).

\section{Results}

Literature search

The initial literature search retrieved 76 relevant articles (duplicates were discarded). After a careful screening of the titles, 50 articles were excluded for 


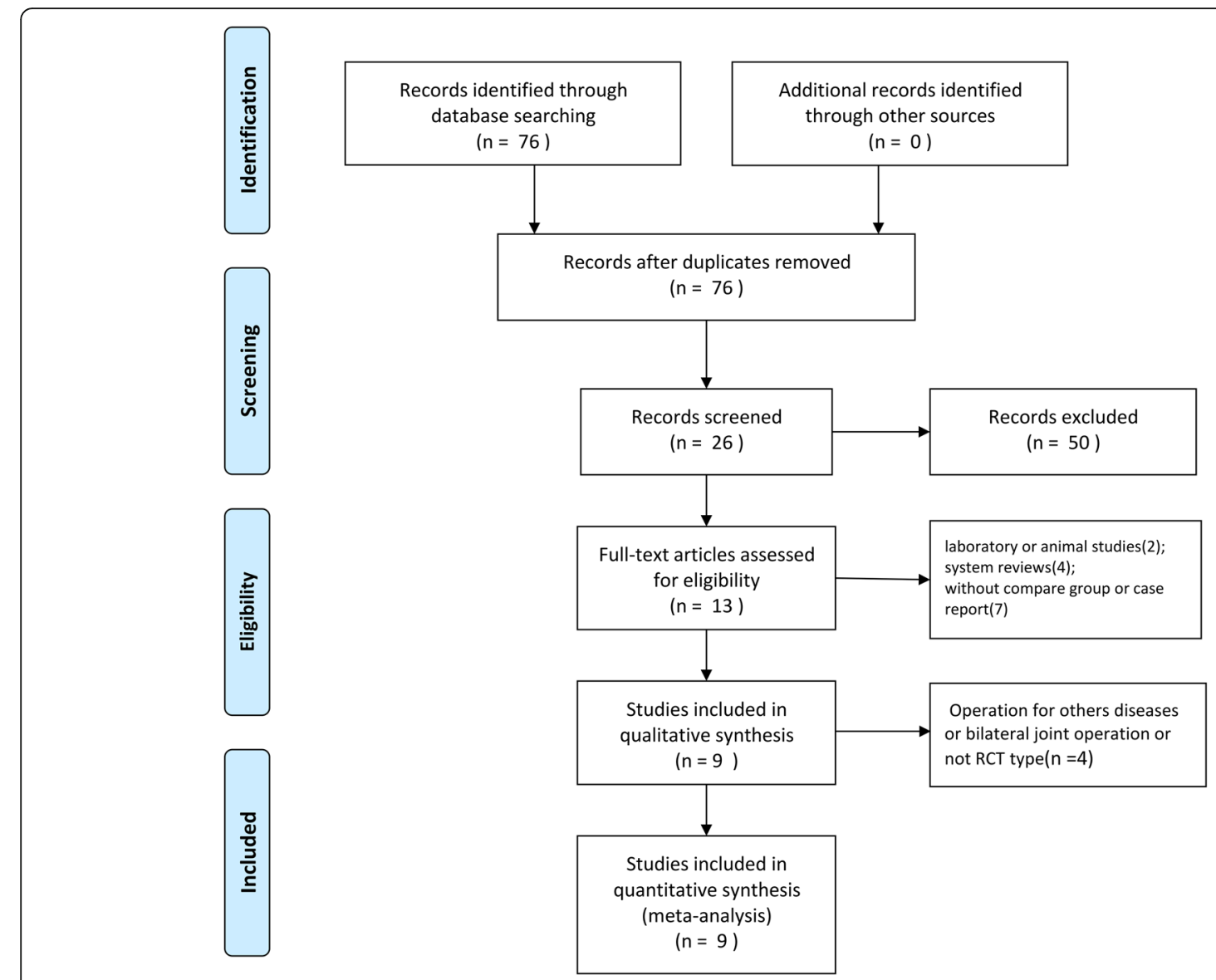

Fig. 1 Search strategy flow diagram

Table 1 The information of included studies

\begin{tabular}{|c|c|c|c|c|c|}
\hline Study & Country & $\mathrm{H} / \mathrm{K}$ & Placebo & TXA & TXA administration \\
\hline Wang et al. 2018 [18] & China & K & 0 & $\begin{array}{l}\text { Once: } 50 \\
\text { Twice:50 } \\
\text { Thrice:50 } \\
\text { Quartic:50 }\end{array}$ & $\begin{array}{l}\text { Once: } 2 \mathrm{~g} \text { at } 2 \mathrm{~h} \text { pre-operatively } \\
\text { Twice: } 2 \mathrm{~g} \text { at } 2 \mathrm{~h} \text { pre-operatively and } 1 \mathrm{~g} \text { at } 3 \mathrm{~h} \text { post-operatively } \\
\text { Thrice: } 2 \mathrm{~g} \text { at } 2 \mathrm{~h} \text { pre-operatively and } 1 \mathrm{~g} \text { at } 3 \text { and } 9 \mathrm{~h} \text { post-operatively } \\
\text { Quartic: } 2 \mathrm{~g} \text { at } 2 \mathrm{~h} \text { pre-operatively and } 1 \mathrm{~g} \text { at } 3,9 \text {, and } 15 \mathrm{~h} \text { post-operatively }\end{array}$ \\
\hline Wang et al. (H1) 2019 [19] & China & $\mathrm{H}$ & 0 & $\begin{array}{l}\text { Once: } 50 \\
\text { Twice: } 50 \\
\text { Thrice: } 50 \\
\text { Quartic:50 }\end{array}$ & $\begin{array}{l}\text { Once: } 2 \mathrm{~g} \text { at } 2 \mathrm{~h} \text { pre-operatively } \\
\text { Twice: } 2 \mathrm{~g} \text { at } 2 \mathrm{~h} \text { pre-operatively and } 1 \mathrm{~g} \text { at } 3 \mathrm{~h} \text { post-operatively } \\
\text { Thrice: } 2 \mathrm{~g} \text { at } 2 \mathrm{~h} \text { pre-operatively and } 1 \mathrm{~g} \text { at } 3 \text { and } 9 \mathrm{~h} \text { post-operatively } \\
\text { Quartic: } 2 \mathrm{~g} \text { at } 2 \mathrm{~h} \text { pre-operatively and } 1 \mathrm{~g} \text { at } 3,9 \text {, and } 15 \mathrm{~h} \text { post-operatively }\end{array}$ \\
\hline Tang et al. 2019 [16] & China & K & 0 & $\begin{array}{l}\text { Once: } 50 \\
\text { Twice: } 50 \\
\text { Quartic:51 }\end{array}$ & $\begin{array}{l}\text { Once: } 2 \mathrm{~g} \text { at } 2 \mathrm{~h} \text { pre-operatively } \\
\text { Twice: } 2 \mathrm{~g} \text { at } 2 \mathrm{~h} \text { pre-operatively and } 4 \mathrm{~h} \text { post-operatively } \\
\text { Quartic: } 2 \mathrm{~g} \text { at } 2 \mathrm{~h} \text { pre-operatively and } 4,10 \text {, and } 16 \mathrm{~h} \text { post-operatively }\end{array}$ \\
\hline Wang et al. (H2) 2019 [20] & China & $\mathrm{H}$ & 60 & $\begin{array}{l}\text { Twice: } 60 \\
\text { Thrice: } 60 \\
\text { Quartic: } 60 \\
\text { Quintic: } 60\end{array}$ & $\begin{array}{l}\text { Twice: } 2 \mathrm{~g} \text { at } 2 \mathrm{~h} \text { pre-operatively and } 1 \mathrm{~g} \text { at } 3 \mathrm{~h} \text { post-operatively } \\
\text { Thrice: } 2 \mathrm{~g} \text { at } 2 \mathrm{~h} \text { pre-operatively and } 1 \mathrm{~g} \text { at } 3 \text { and } 7 \mathrm{~h} \text { post-operatively } \\
\text { Quartic: } 2 \mathrm{~g} \text { at } 2 \mathrm{~h} \text { pre-operatively and } 1 \mathrm{~g} \text { at } 3,7, \text { and } 11 \mathrm{~h} \text { post-operatively } \\
\text { Quintic: } 2 \mathrm{~g} \text { at } 2 \mathrm{~h} \text { pre-operatively and } 1 \mathrm{~g} \text { at } 3,7,11 \text {, and } 15 \mathrm{~h} \text { post-operatively }\end{array}$ \\
\hline Wang et al. 2019 [17] & China & K & 55 & $\begin{array}{l}\text { Twice:55 } \\
\text { Thrice:55 } \\
\text { Quartic:55 } \\
\text { Quintic:55 }\end{array}$ & $\begin{array}{l}\text { Twice: } 2 \mathrm{~g} \text { at } 2 \mathrm{~h} \text { pre-operatively and } 1 \mathrm{~g} \text { at } 3 \mathrm{~h} \text { post-operatively } \\
\text { Thrice: } 2 \mathrm{~g} \text { at } 2 \mathrm{~h} \text { pre-operatively and } 1 \mathrm{~g} \text { at } 3 \text { and } 7 \mathrm{~h} \text { post-operatively } \\
\text { Quartic: } 2 \mathrm{~g} \text { at } 2 \mathrm{~h} \text { pre-operatively and } 1 \mathrm{~g} \text { at } 3,7, \text { and } 11 \mathrm{~h} \text { post-operatively } \\
\text { Quintic: } 2 \mathrm{~g} \text { at } 2 \mathrm{~h} \text { pre-operatively and } 1 \mathrm{~g} \text { at } 3,7,11 \text {, and } 15 \mathrm{~h} \text { post-operatively }\end{array}$ \\
\hline Cao et al. 2019 [15] & China & $\mathrm{H}$ & 0 & $\begin{array}{l}\text { Once: } 51 \\
\text { Twice: } 51 \\
\text { Quartic:50 }\end{array}$ & $\begin{array}{l}\text { Once: } 2 \mathrm{~g} \text { at } 2 \mathrm{~h} \text { pre-operatively } \\
\text { Twice: } 2 \mathrm{~g} \text { at } 2 \mathrm{~h} \text { pre-operatively and } 4 \mathrm{~h} \text { post-operatively } \\
\text { Quartic: } 2 \mathrm{~g} \text { at } 2 \mathrm{~h} \text { pre-operatively and } 4,10 \text {, and } 16 \mathrm{~h} \text { post-operatively }\end{array}$ \\
\hline Yuan et al. 2017 [21] & China & K & 140 & Twice:140 & Twice: $2 \mathrm{mg} / \mathrm{kg}$ at $2 \mathrm{~h}$ pre-operatively and $12 \mathrm{~h}$ post-operatively \\
\hline Zhao et al. 2018 [22] & China & $\mathrm{H}$ & 40 & Twice:40 & Twice: $2 \mathrm{mg} / \mathrm{kg}$ at $2 \mathrm{~h}$ pre-operatively and $3 \mathrm{~h}$ post-operatively \\
\hline Zohar et al. 2004 [23] & China & K & 20 & Quartic:20 & Quartic: $1 \mathrm{~g}$ at $1 \mathrm{~h}$ pre-operatively and 6, 12 , and $18 \mathrm{~h}$ post-operatively \\
\hline
\end{tabular}




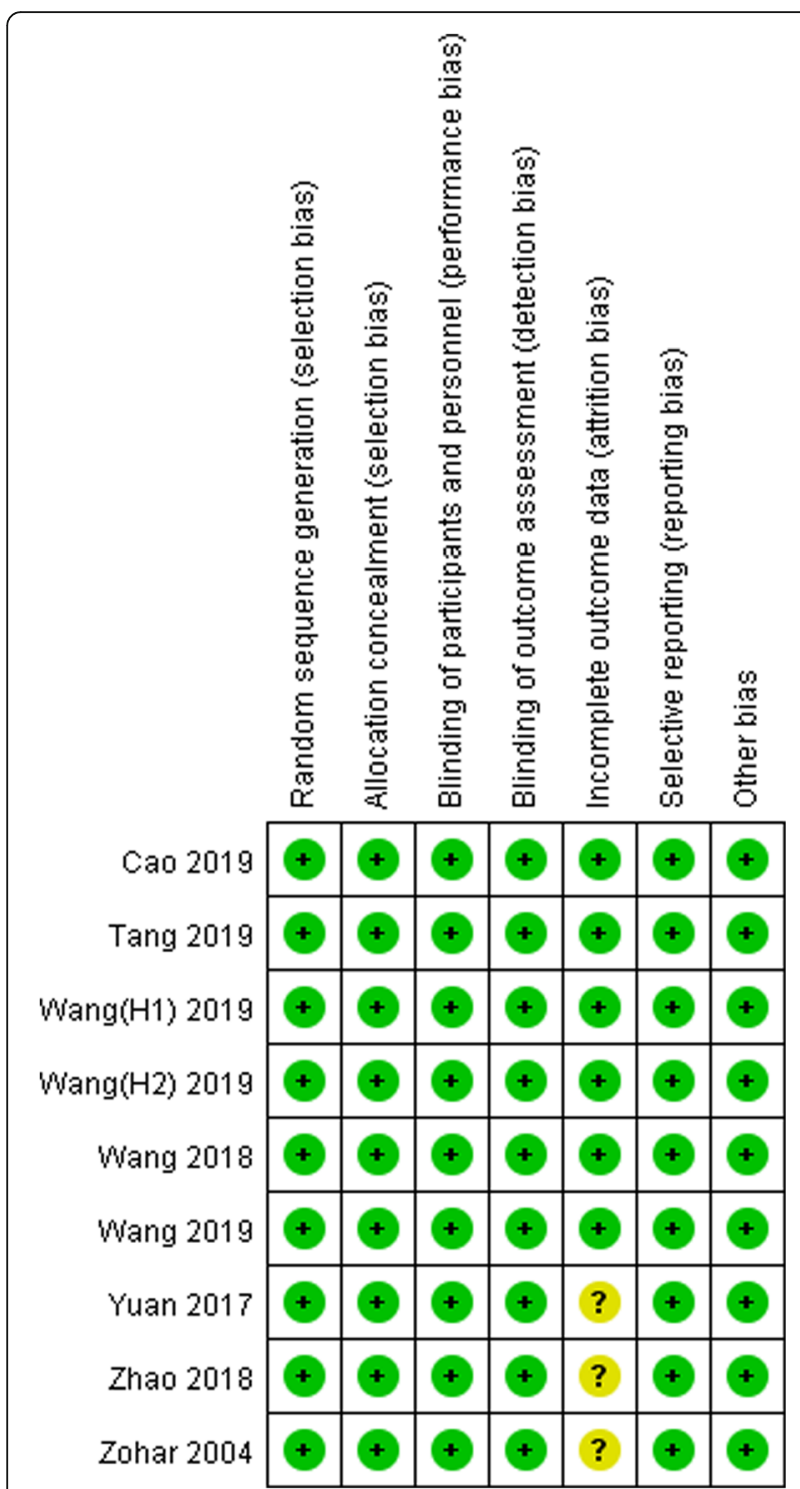

Fig. 2 Summarizes the methodological quality of the selected studies not investigating the topic of interest. After reviewing the abstracts, 13 articles were excluded (2 laboratory or animal studies, 4 not RCT type, 7 without compare group or case report). After reading full articles, 4 studies were excluded for the operation for other diseases or bilateral joint operation or not RCT type. Therefore, leaving 9 studies that matched the selection criteria and were suitable for meta-analysis (Fig. 1). A total of 1678 (TXA 1363 (once, 201; twice, 496; thrice, 215; quartic, 336; quintic, 115); placebo 315) patients were enrolled in the studies, and the information of the included studies is summarized in Table 1 [15-23]. They are all RCT studies and the methodological bias of this study was low (Fig. 2).

\section{Main analysis}

Nine studies involving 1678 patients were included in this meta-analysis. Our results showed that oral TXA could significantly reduce the total blood loss (TLB), intraoperative blood loss (IBL), decline of hemoglobin (DHB), length of hospital stay (LOS), and transfusion rate $([\mathrm{MD}=-496.94,95 \% \mathrm{CI}$ (611.41 to -382.47$), P<0.001]$; $[\mathrm{MD}=-118.5,95 \%$ CI $(-166.77$ to -70.24$), P<0.001]$; [MD $=-13.06$, 95\% CI $(-17.67$ to -8.45$), P<0.001] ;[\mathrm{MD}=-$ $0.12,95 \%$ CI $(-0.17$ to -0.06$), P<0.001]$; $[\mathrm{OR}=$ $0.26,95 \%$ CI (0.16 to 0.43$), P<0.001])$ and did not increase the incidence of DVT and IVT in total joint replacement patients $([\mathrm{OR}=1.05,95 \% \mathrm{CI} \quad(0.58$ to $1.88), P=0.88]$; $[\mathrm{OR}=1.62,95 \% \mathrm{CI}(0.52$ to 4.99$)$, $P=0.40]$ ). Moreover, the effectiveness of oral TXA administration increases as the number of administrations increases. Compared with one administration of oral TXA, two administrations of TXA significantly reduced total blood loss (TBL) and decreased hemoglobin (DHB). In addition, three administrations of oral TXA were more effective than two administrations of oral TXA, and four administrations of TXA were better than three administrations of

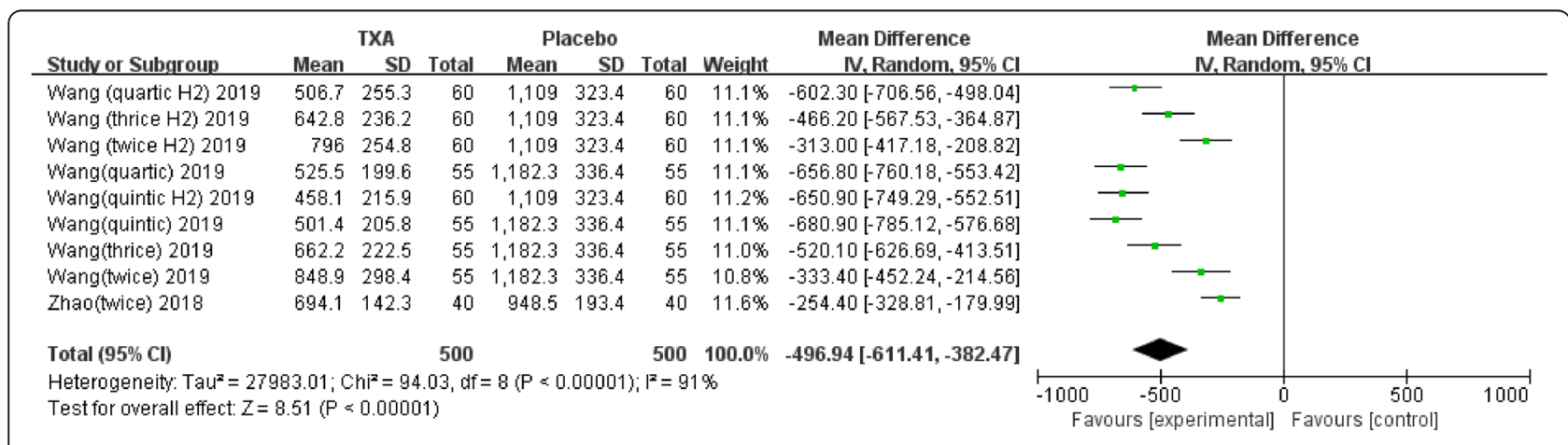

Fig. 3 Forest plot showing the weighted mean difference in total blood loss (TBL) between oral and placebo groups 


\begin{tabular}{|c|c|c|c|c|c|c|c|c|c|c|c|c|}
\hline Studv or Subgroup & Mean & \multicolumn{2}{|l|}{ TXA } & \multicolumn{2}{|c|}{ Placebo } & Total & Weight & $\begin{array}{l}\text { Mean Difference } \\
\quad \text { IV, Random, } 95 \% \mathrm{Cl}\end{array}$ & \multicolumn{4}{|c|}{$\begin{array}{c}\text { Mean Difference } \\
\mathrm{N}, \text { Random, } 95 \% \mathrm{Cl}\end{array}$} \\
\hline Wang (quartic H2) 2019 & 138.9 & 35.3 & 60 & 282.5 & 39.2 & 60 & $20.0 \%$ & $-143.60[-156.95,-130.25]$ & & \multirow{6}{*}{--} & & \\
\hline Wang (thrice H2) 2019 & 139.9 & 40 & 60 & 282.5 & 39.2 & 60 & $20.0 \%$ & $-142.60[-156.77,-128.43]$ & & & & \\
\hline Wang (twice H2) 2019 & 138.6 & 38.5 & 60 & 282.5 & 39.2 & 60 & $20.0 \%$ & $-143.90[-157.80,-130.00]$ & & & & \\
\hline Wang(quintic H2) 2019 & 141.5 & 36.8 & 60 & 282.5 & 39.2 & 60 & $20.0 \%$ & $-141.00[-154.60,-127.40]$ & & & & \\
\hline Zhao(twice) 2018 & 134.8 & 24.15 & 40 & 156.3 & 35.9 & 40 & $20.0 \%$ & $-21.50[-34.91,-8.09]$ & & & & \\
\hline \multirow{2}{*}{\multicolumn{8}{|c|}{$\begin{array}{l}\text { Total }(95 \% \mathrm{Cl}) \\
\text { Heterogeneity: Tau }=2983.51 ; \mathrm{Chi}^{2}=248.97 \text {, df } \\
\text { Test for overall effect: } Z=4.81(\mathrm{P} \approx 0.00001)\end{array}$}} & $-118.50[-166.77,-70.24]$ & & & & \\
\hline & & & & & & & & & $\begin{array}{l}-200 \\
\text { Favour }\end{array}$ & $\begin{array}{cc}-100 & 0 \\
\text { is [experimental] }\end{array}$ & $\begin{array}{c}100 \\
\text { Favours [control] }\end{array}$ & 200 \\
\hline
\end{tabular}

TXA. Six studies suggested that a greater number of administrations of oral TXA administration were more effective at decreasing the blood loss (Figs. 3, $4,5,6,7,8,9,10$ and 11).

\section{Discussion}

Our results showed that compared with placebo, oral TXA could significantly reduce the total blood loss, intraoperative blood loss, decline of hemoglobin, transfusion rate, and length of hospital stay. In addition, oral TXA did not increase the incidence of DVT and IVT for total joint replacement patients. Furthermore, the effectiveness of oral TXA administration increases as the number of administrations increases, and there was no evidence that oral TXA was associated with a high risk of side effects. Thus, we considered oral TXA to be an effective method to reduce blood loss, and a greater number of administrations of oral TXA at different time points during the operation were more beneficial for patients who received total joint arthroplasty.

Perioperative blood loss is a common complication for total joint arthroplasty patients, which might result in swelling and stiffness and prolong the time of rehabilitation $[24,25]$. To overcome this problem, various techniques have been used to control blood loss during surgery. Currently, allogeneic blood transfusions are a popular and effective method for improving patients' postoperative HB levels and are accepted in many major orthopedic surgeries [26-28]. However, transfusion might result in the reaction of the immune system and increase the risk of infection, and several side effects have been reported in previous studies. Thus, there is an urgent need for an effective and safe method to help reduce blood loss during surgery [29, 30].

TXA is an antifibrinolytic drug that has been demonstrated to effectively reduce total blood loss for patients who received major orthopedic surgery in many previous publications [31]. However, the majority of reports have focused on topical and intravenous TXA administration or the combination of the two application methods, and many previous studies have confirmed that there are no significant differences in terms of effectiveness and safety in decreasing blood loss and transfusion rates between the two administration procedures. However, little is known about oral TXA administration in primary total joint replacement, and some researchers believe that multiple administrations or high doses of TXA can maintain the drug concentration and result in better outcomes. To date, however, there is not enough evidence to support these views [32, 33].

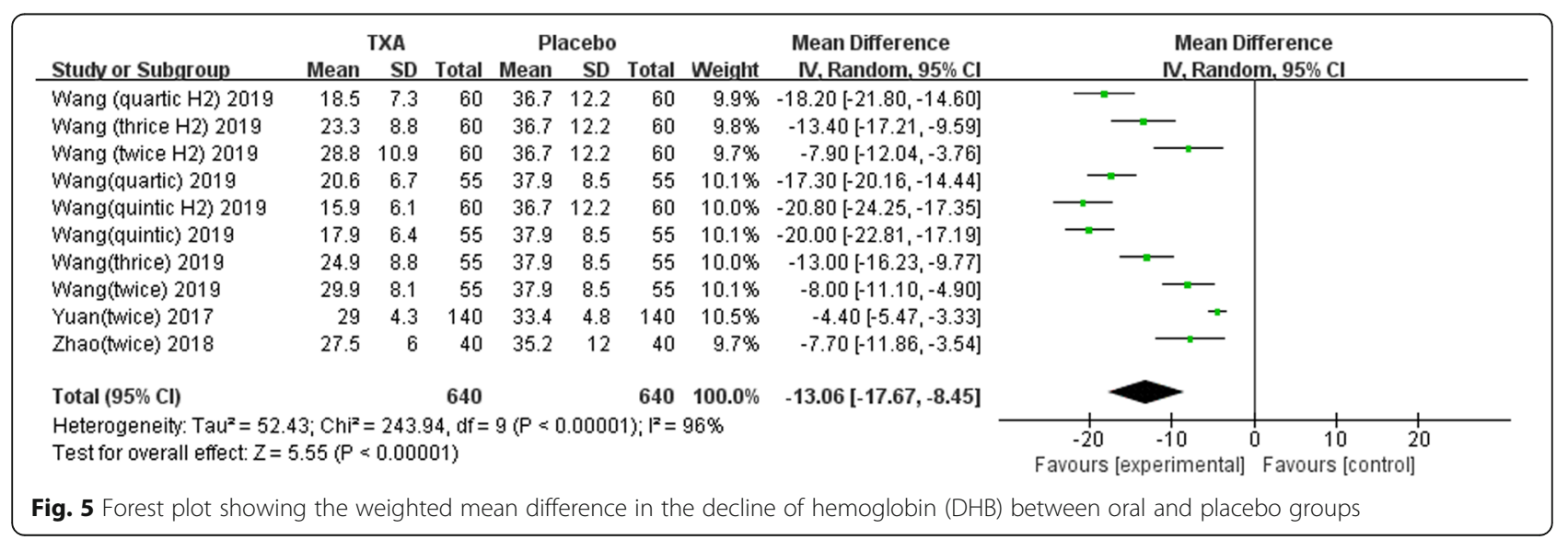




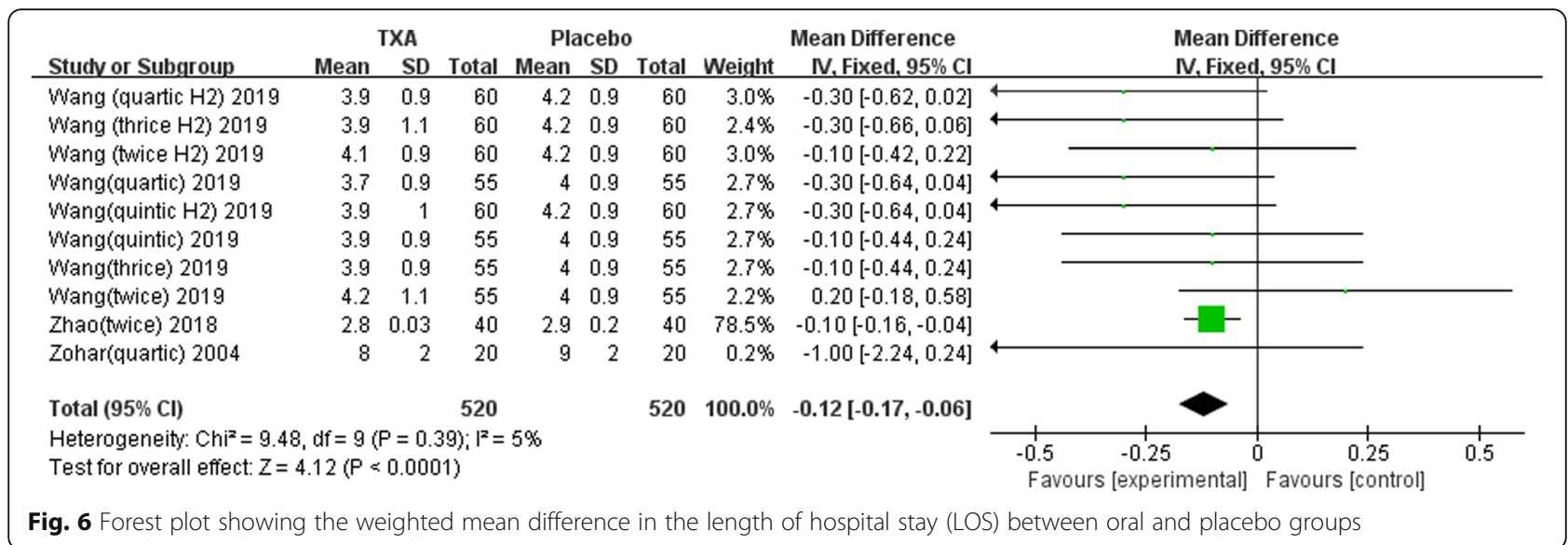

Thus, we conducted this research to investigate the relationship between multiple administrations of oral TXA and blood loss in total joint replacement patients. To ensure the accuracy of the results, only RCTs were included in our research. Our results suggested that oral TXA was an effective method to control perioperative blood loss and did not increase the risk of IVT or DVT. In addition, we found that the effectiveness of oral TXA administration increases as the number of administrations increases and that there was an upper limit (five administrations). Furthermore, we found that five administrations lead to better outcomes than four administrations, but there is a lack of enough data for analysis (only two reports); therefore, there is a need for more high-quality RCT studies in the future to support this view.

Although oral TXA was associated with an increased reduction of the blood loss, there is still no consensus on the optimal timing and total dose of oral TXA. In our research, the included studies reported different standard applications of oral TXA.
Six studies recommended $2 \mathrm{~g}$ TXA as the basic dose, and one recommended $1 \mathrm{~g}$, while two studies adopted $20 \mathrm{mg} / \mathrm{kg}$ doses of TXA. In addition, the included studies administered TXA at different time points between pre- and postoperation, and none of the studies reported data beyond $24 \mathrm{~h}$ postoperatively. The repeated administrations included two, three, four, and five administrations. Furthermore, there was no standard for the total dose of TXA application because of the different timing and dosing standards applied in the included studies; therefore, we consider that it is difficult to determine the best total dose and time point of oral TXA administration in total joint replacement patients. However, through our gross analysis, the results demonstrated that $2 \mathrm{~g}$ TXA as a basic dose was an effective and safe method to reduce blood loss during total joint replacement and that repeated administrations in the first $24 \mathrm{~h}$ postoperatively are more effective.

Many previous studies have demonstrated the safety and efficacy of TXA administration through different routes in TKA or THA, but several complications

\begin{tabular}{|c|c|c|c|c|c|c|c|c|c|c|c|}
\hline Study or Subgroup & $\begin{array}{l}\text { TXA } \\
\text { Events }\end{array}$ & Total & $\begin{array}{l}\text { Placeb } \\
\text { Events }\end{array}$ & $\begin{array}{l}\text { bo } \\
\text { Total }\end{array}$ & Weight & $\begin{array}{c}\text { Odds Ratio } \\
\text { M-H, Fixed, } 95 \% \mathrm{Cl}\end{array}$ & & & $\begin{array}{r}\text { Odds R } \\
\text { M-H, Fixed }\end{array}$ & $\begin{array}{l}\text { Ratio } \\
\text { d, } 95 \% \mathrm{Cl}\end{array}$ & \\
\hline Wang (quartic H2) 2019 & 2 & 60 & 1 & 60 & $19.8 \%$ & $2.03[0.18,23.06]$ & & & & 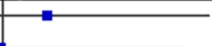 & \\
\hline Wang (thrice H2) 2019 & 1 & 60 & 1 & 60 & $20.2 \%$ & $1.00[0.06,16.37]$ & & & & & \\
\hline Wang (twice H2) 2019 & 2 & 60 & 1 & 60 & $19.8 \%$ & $2.03[0.18,23.06]$ & & & & & \\
\hline Wang(quintic H2) 2019 & 2 & 60 & 1 & 60 & $19.8 \%$ & $2.03[0.18,23.06]$ & & & & & \\
\hline Yuan(twice) 2017 & 1 & 140 & 1 & 140 & $20.4 \%$ & $1.00[0.06,16.15]$ & & & & & \\
\hline Total (95\% Cl) & & 380 & & 380 & $100.0 \%$ & $1.62[0.52,4.99]$ & & & & & \\
\hline Total events & 8 & & 5 & & & & & & & & \\
\hline \multicolumn{7}{|c|}{$\begin{array}{l}\text { Heterogeneity: } \mathrm{Chi}^{2}=0.33, \mathrm{df}=4(\mathrm{P}=0.99) ; \mathrm{I}^{2}=0 \% \\
\text { Test for overall effect: } Z=0.83(\mathrm{P}=0.40)\end{array}$} & ${ }^{0.01} \mathrm{~F}$ & $\begin{array}{l}0.1 \\
{[\exp }\end{array}$ & erimental] & Favours [control] & 100 \\
\hline
\end{tabular}




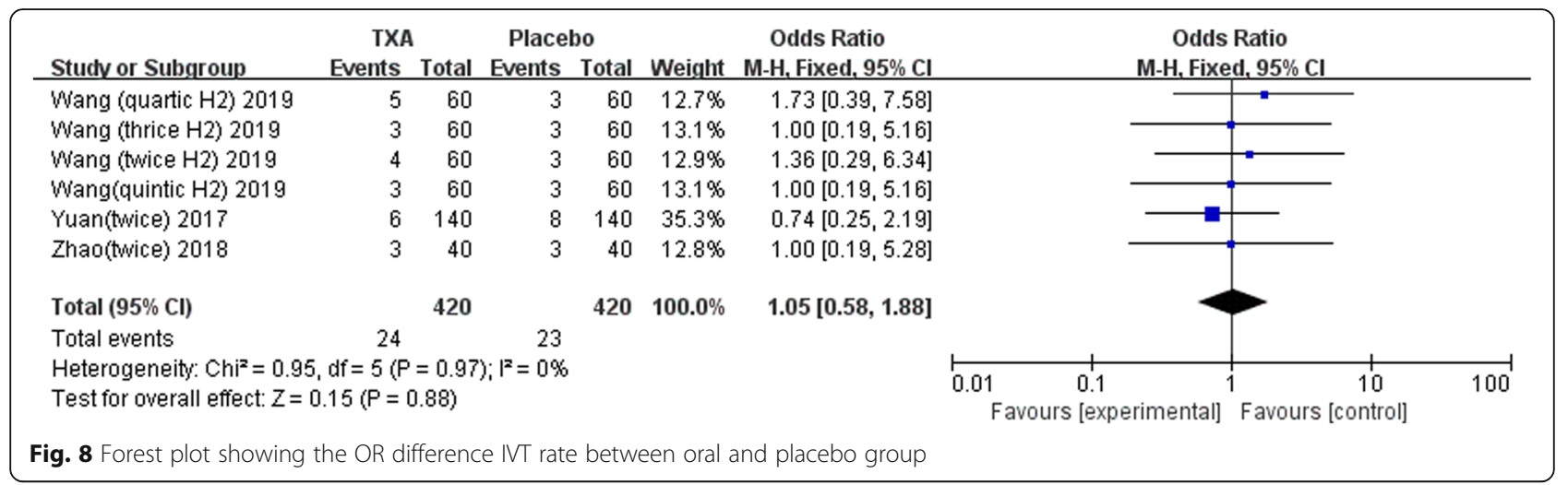

remain, especially the incidence of deep vein thrombosis (DVT) and intramuscular venous thrombosis (IVT) [34]. In addition, some studies considered that intravenous TXA application was associated with cardiovascular disease or renal dysfunction, which have not been recorded in studies of oral TXA [35]. Our results suggested that there were no significant differences in terms of the incidence of DVT and IVT between the placebo and oral TXA treatments (including all more repeat administration groups). Thus, we thought more administrations of oral TXA did not increase the risk of DVT and IVT compared with the placebo group.

However, this research still has some limitations. First, this meta-analysis only included nine studies, and the surgeons all came from China. Most of them were working in the same hospital (West China Hospital), which may have caused bias in the results. Second, the dosing and timing of TXA administration differed across studies, which may have affected the accuracy of the final results. Third, all included studies lacked long-term follow-up, which may have decreased the reliability of the results. Although this meta-analysis contains various limitations, all included studies were high-quality RCT studies, which means that the results are still powerful enough to support our views. Nevertheless, more multicenter, prospective, randomized control trials with large sample sizes are needed in the future.

\section{Conclusion}

Our results suggested that oral TXA could significantly reduce the blood loss, length of hospital stay, and does not increase DVT and IVT incidence for total joint replacement patients; meanwhile, more times of oral TXA administration are more effective.

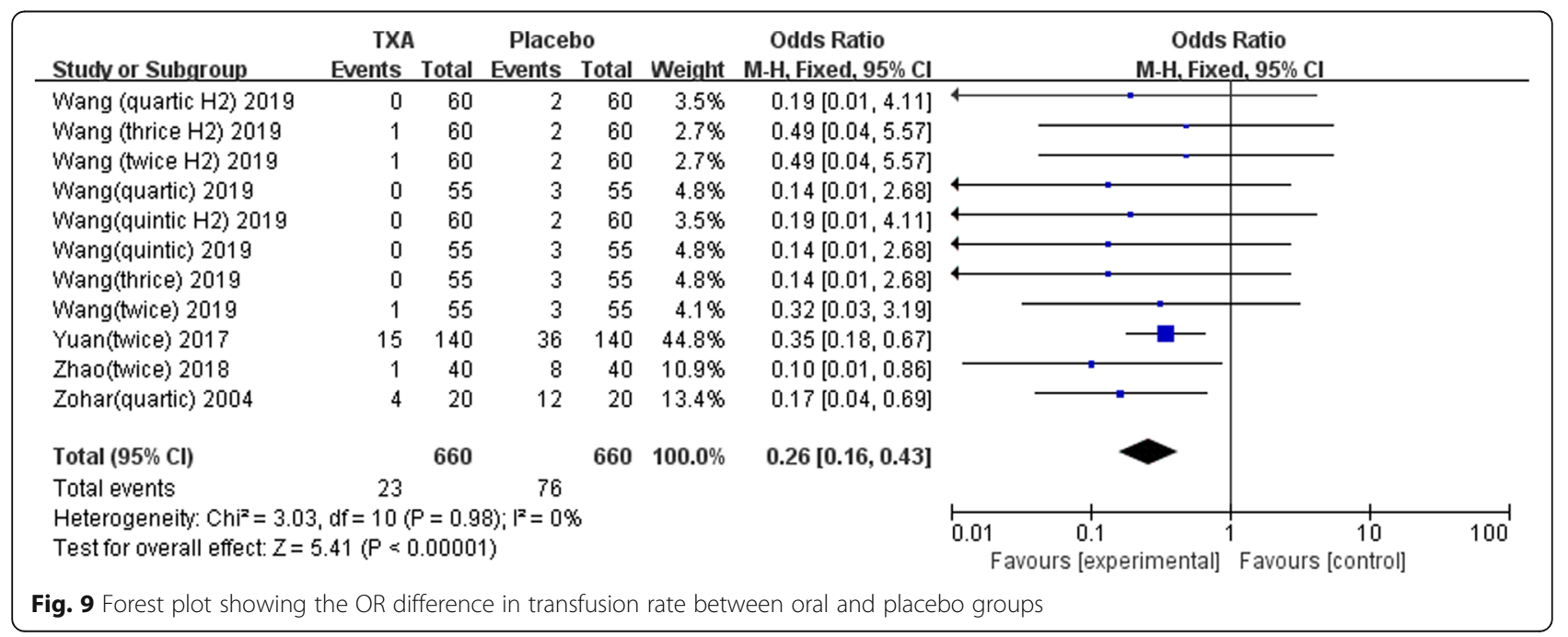




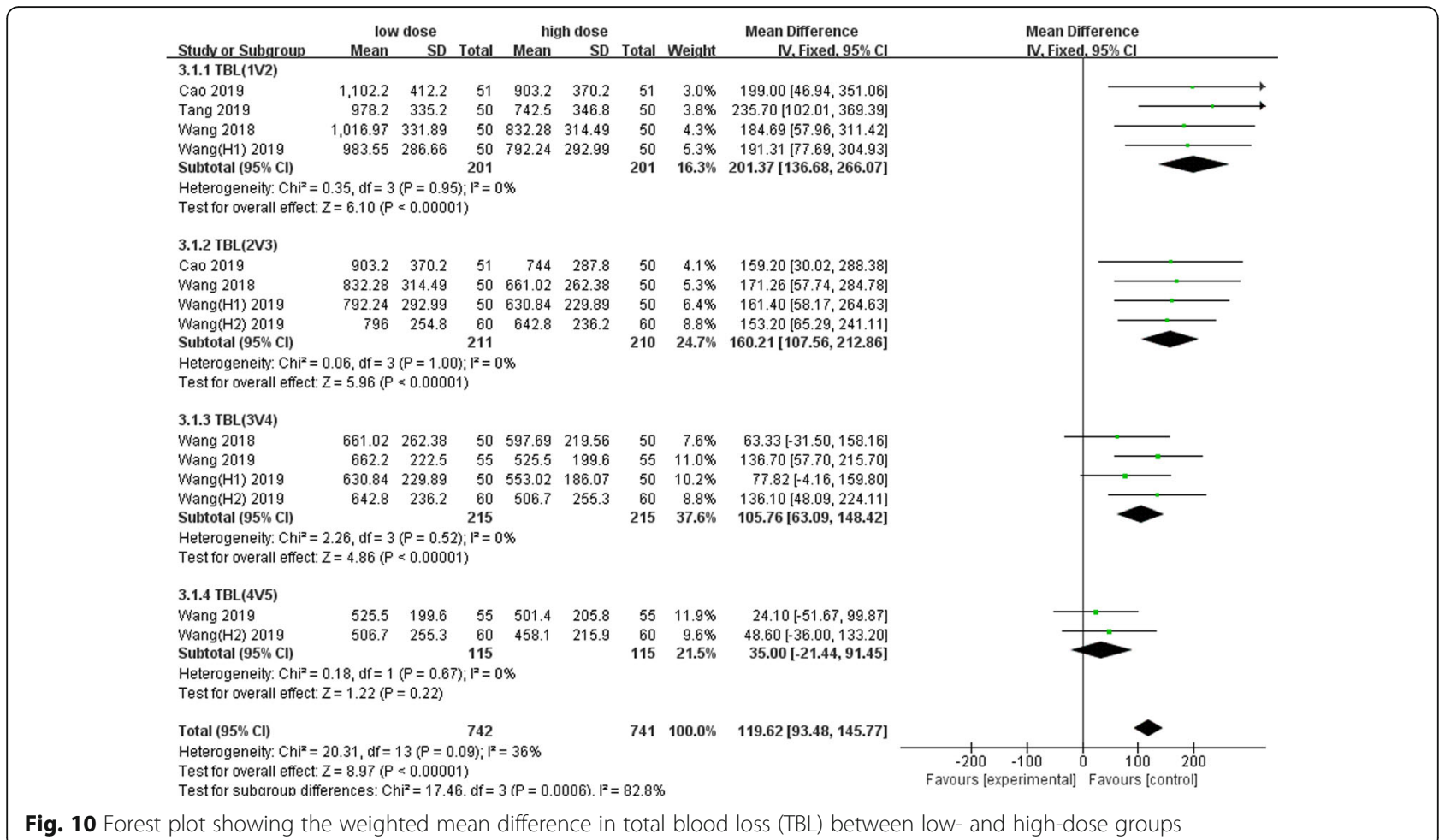

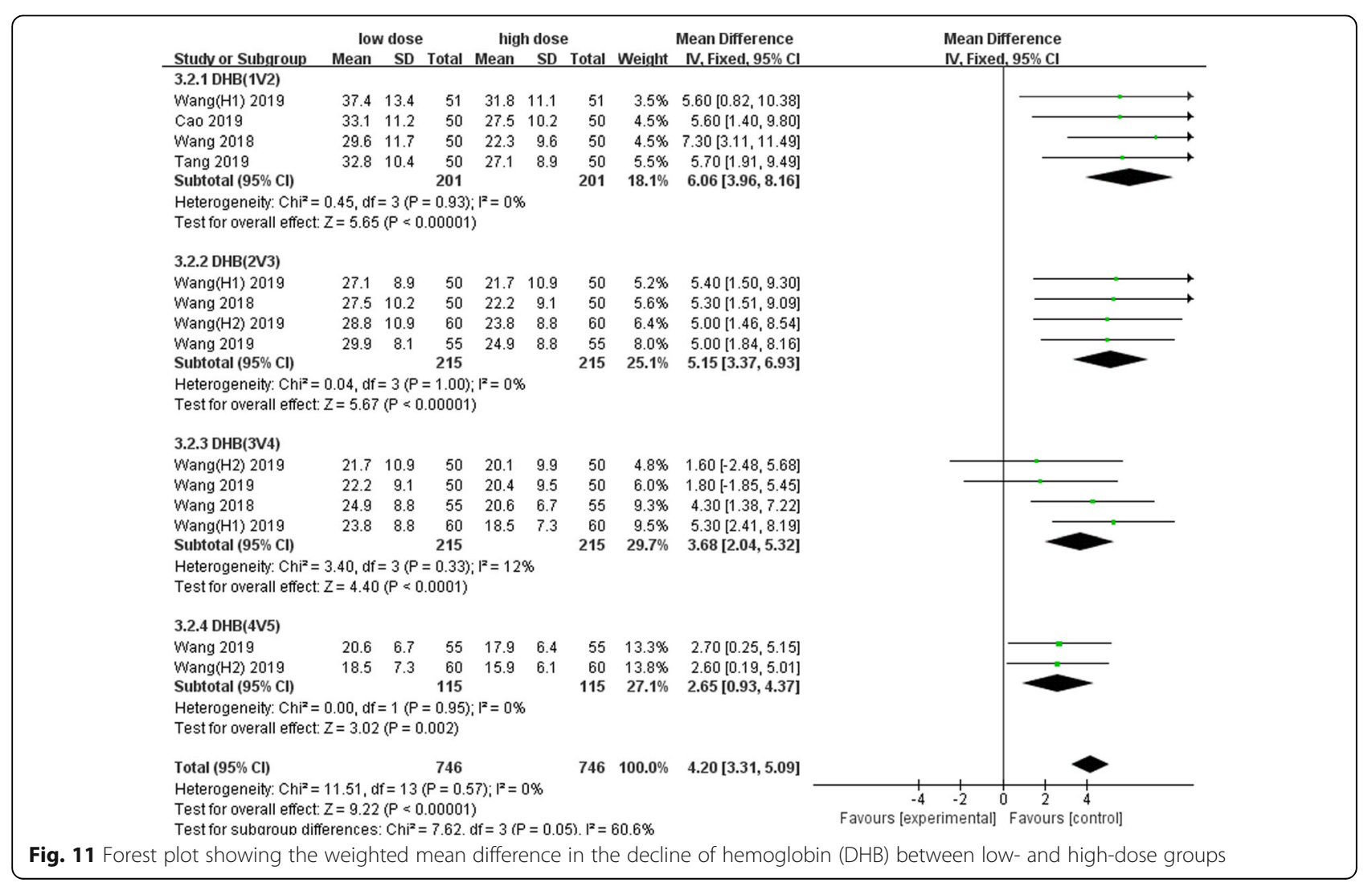




\section{Abbreviations}

TXA: Tranexamic acid; TBL: Total blood loss; DHB: Decline of hemoglobin; HS: Hospital stay; IVT: Intramuscular venous thrombosis; DVT: Deep vein thrombosis; TKA/THA: Total knee/hip arthroplasty; TKR/THR: Total knee/hip replacement; RRs: Relative risks; Cls: Confidence intervals

\section{Acknowledgements}

There is no external assistance for the study.

\section{Authors' contributions}

All authors have contributed substantially to the conception, design, analysis, and/or interpretation of the data in this manuscript and will take public responsibility for the content and the author(s) read and approved the final manuscript.

\section{Funding}

This study has no funding.

\section{Availability of data and materials}

All authors consent for availability of data and materials.

\section{Ethics approval and consent to participate}

This is a review study which does not need an ethics approval and consent to participate.

\section{Consent for publication}

All authors consent for publication.

\section{Competing interests}

There have no competing interests.

\section{Author details}

'Department of Orthopedics Medicine, Wujin Hospital Affiliated with Jiangsu University, Changzhou 213000, China. '2Department of Respiratory Medicine, The Wujin Clinical college of Xuzhou Medical University, Changzhou 213000, China.

Received: 12 June 2020 Accepted: 23 September 2020

Published online: 06 October 2020

\section{References}

1. Xie J, et al. Multiple boluses of intravenous tranexamic acid to reduce hidden blood loss after primary total knee arthroplasty without tourniquet: a randomized clinical trial. J Arthroplasty. 2016;31(11):2458-64

2. Rosencher N, et al. Orthopedic Surgery Transfusion Hemoglobin European Overview (OSTHEO) study: blood management in elective knee and hip arthroplasty in Europe. Transfusion. 2003:43(4):459-69.

3. Ma J, et al. Blood management of staged bilateral total knee arthroplasty in a single hospitalization period. J Orthop Surg Res. 2014;9:116.

4. Themistoklis T, et al. Perioperative blood management strategies for patients undergoing total knee replacement: where do we stand now? World J Orthop. 2017:8(6):441-54

5. Tai TW, et al. Effects of tourniquet use on blood loss and soft-tissue damage in total knee arthroplasty: a randomized controlled trial. J Bone Joint Surg Am. 2012;94(24):2209-15

6. Chen JY, et al. Intravenous versus intra-articular tranexamic acid in total knee arthroplasty: a double-blinded randomised controlled noninferiority trial. Knee. 2016:23(1):152-6.

7. Jamil MT, et al. Transfusion-related acute lung injury in a paediatric intensive care unit of Pakistan. J Ayub Med Coll Abbottabad. 2017;29(4):702-5.

8. Ponnusamy KE, Kim TJ, Khanuja HS. Perioperative blood transfusions in orthopaedic surgery. J Bone Joint Surg Am. 2014;96(21):1836-44.

9. Bedard NA, et al. Recent trends in blood utilization after primary hip and knee arthroplasty. J Arthroplasty. 2017;32(3):724-7.

10. Wu Y, et al. Blood loss and cost-effectiveness of oral vs intravenous tranexamic acid in primary total hip arthroplasty: a randomized clinical trial. Thromb Res. 2018;171:143-8.

11. King $L$, et al. Comparison of oral vs. combined topical/intravenous/oral tranexamic acid in the prevention of blood loss in total knee arthroplasty: a randomised clinical trial. Orthop Traumatol Surg Res. 2019;105(6):1073-7.
12. Krauss ES, et al. Use of Intravenous Tranexamic Acid Improves Early Ambulation After Total Knee Arthroplasty and Anterior and Posterior Total Hip Arthroplasty. Am J Orthop (Belle Mead NJ). 2017;46(5):E314-9.

13. Wilde $J M$, et al. One dose of intravenous tranexamic acid is equivalent to two doses in total hip and knee arthroplasty. J Bone Joint Surg Am. 2018; 100(13):1104-9.

14. Lopez-Hualda A, et al. Efficacy and safety of topical tranexamic acid in knee arthroplasty. Med Clin (Barc). 2018;151(11):431-4.

15. Cao G, et al. The efficacy and safety of multiple-dose oral tranexamic acid on blood loss following total hip arthroplasty: a randomized controlled trial. Int Orthop. 2019:43(2):299-305.

16. Tang $Y$, et al. The efficacy and safety of multiple doses of oral tranexamic acid on blood loss, inflammatory and fibrinolysis response following total knee arthroplasty: a randomized controlled trial. Int J Surg. 2019;65:45-51.

17. Wang $D$, et al. The antifibrinolytic and anti-inflammatory effects of multiple doses of oral tranexamic acid in total knee arthroplasty patients: a randomized controlled trial. J Thromb Haemost. 2018;16(12):2442-53.

18. Wang $D$, et al. Blood-conserving efficacy of multiple doses of oral tranexamic acid associated with an enhanced-recovery programme in primary total knee arthroplasty: a randomized controlled trial. Bone Joint J. 2018:100-B(8):1025-32.

19. Wang $D$, et al. Finding the optimal regimen for oral tranexamic acid administration in primary total hip arthroplasty: a randomized controlled trial. J Bone Joint Surg Am. 2019;101(5):438-45.

20. Wang $D$, et al. Effect of multiple doses of oral tranexamic acid on haemostasis and inflammatory reaction in total hip arthroplasty: a randomized controlled trial. Thromb Haemost. 2019;119(1):92-103.

21. Yuan $X$, et al. Comparison of 3 routes of administration of tranexamic acid on primary unilateral total knee arthroplasty: a prospective, randomized, controlled study. J Arthroplasty. 2017;32(9):2738-43.

22. Zhao $\mathrm{H}$, et al. Efficacy of oral tranexamic acid on blood loss in primary total hip arthroplasty using a direct anterior approach: a prospective randomized controlled trial. Int Orthop. 2018;42(11):2535-42.

23. Zohar $\mathrm{E}$, et al. The postoperative blood-sparing efficacy of oral versus intravenous tranexamic acid after total knee replacement. Anesth Analg 2004:99(6):1679-83 table of contents.

24. Wang $D$, et al. Closed suction drainage is not associated with faster recovery after total knee arthroplasty: a prospective randomized controlled study of 80 patients. Orthop Surg. 2016;8(2):226-33.

25. Irwin A, et al. Oral versus intravenous tranexamic acid in enhanced-recovery primary total hip and knee replacement: results of 3000 procedures. Bone Joint J. 2013;95-B(11):1556-61.

26. Cao $\mathrm{G}$, et al. Incidence and risk factors for blood transfusion in simultaneous bilateral total joint arthroplasty: a multicenter retrospective study. J Arthroplasty. 2018:33(7):2087-91.

27. Bong MR, et al. Risks associated with blood transfusion after total knee arthroplasty. J Arthroplasty. 2004;19(3):281-7.

28. Slover J, et al. Incidence and risk factors for blood transfusion in total joint arthroplasty: analysis of a statewide database. J Arthroplasty. 2017:32(9):2684-2687.e1.

29. Fuller AK, et al. Bacterial culture reduces but does not eliminate the risk of septic transfusion reactions to single-donor platelets. Transfusion. 2009;49(12):2588-93.

30. Song $\mathrm{K}$, et al. The incidence and risk factors for allogenic blood transfusion in total knee and hip arthroplasty. J Orthop Surg Res. 2019;14(1):273.

31. Sassoon A, et al. Tranexamic acid: optimal blood loss management in surface replacement arthroplasty. Bone Joint J. 2016;98-B(2):173-8.

32. Lei $Y$, et al. The efficacy and safety of multiple-dose intravenous tranexamic acid on blood loss following total knee arthroplasty: a randomized controlled trial. Int Orthop. 2017:41(10):2053-9.

33. Iwai $T$, et al. Repeat-dose intravenous tranexamic acid further decreases blood loss in total knee arthroplasty. Int Orthop. 2013:37(3):441-5.

34. Li J, Zhang Z, Chen J. Comparison of efficacy and safety of topical versus intravenous tranexamic acid in total hip arthroplasty: a meta-analysis. Medicine (Baltimore). 2016;95(36):e4689.

35. Kim TK, Chang CB, Koh IJ. Practical issues for the use of tranexamic acid in total knee arthroplasty: a systematic review. Knee Surg Sports Traumatol Arthrosc. 2014;22(8):1849-58

\section{Publisher's Note}

Springer Nature remains neutral with regard to jurisdictional claims in published maps and institutional affiliations. 